\title{
The Relationship between Experiences of Athletic and Daily Life and Personality in Senior High School Students
}

\author{
Daisuke Horii ${ }^{1}$, Enji Okuda² \\ ${ }^{1}$ Faculty of Biomedical Engineering, Osaka Electro-Communication University, Shijonawate, Japan \\ ${ }^{2}$ Faculty of Education, Shiga University, Otsu, Japan \\ Email: horii@osakac.ac.jp
}

How to cite this paper: Horii, D., \& Okuda, E. (2019). The Relationship between Experiences of Athletic and Daily Life and Personality in Senior High School Students. Psychology, 10, 273-284.

https://doi.org/10.4236/psych.2019.103020

Received: December 9, 2018

Accepted: February 18, 2019

Published: February 21, 2019

Copyright (อ 2019 by author(s) and Scientific Research Publishing Inc. This work is licensed under the Creative Commons Attribution International License (CC BY 4.0).

http://creativecommons.org/licenses/by/4.0/ (c) (i) Open Access

\begin{abstract}
No single factor has yet emerged to date in the literature on personality, and it is unlikely that one will ever be found given the diversity of traits subsumed under the category of personality. We hypothesized that experiences of crisis, exploration, and commitment in athletic and daily life events affect personality. This study examined the relationship between experiences of athletic and daily life and personality in Japanese senior high school students by using multiple regression analysis. We had senior high school students (189 males and 118 females) complete a questionnaire assessing their experiences of crisis, exploration, and commitment on four issues (Teammates, Authority Figures, Competition Results, Contest Continuation) in the athletic domain, and on six issues (Study, Future Courses, Values, Family, Opposite Sex Friends, Same Sex Friends) in the daily life domain. Our results reveal that, there are significant models for factors of Extraversion and Neuroticism in males with less than 10 years of experience; for males with over 10 years of experience, there were significant models for factors of Neuroticism. Moreover, for males with less than 10 years of experience, there were significant relationships between personality with regards to exploration in the athletic domain and daily life domain; for males with over 10 years of experience, there were significant relationships between personality with regards to commitment in the athletic domain, crisis, and commitment in the daily life domain. For females with less than 10 years of experience, there was no significant difference; for females with over 10 years of experience, there were significant relationships between personality with regards to crisis in the athletic domain. Thus, there was a more significant relationship between various experiences and personality in males than females. Similar to previous research examining personality, this study highlights the importance of including experiences of crisis, exploration, and commitment when taking part in sports activity.
\end{abstract}




\section{Keywords}

Experiences of Athletic, Experiences of Daily Life, Personality, Senior High School Students

\section{Introduction}

Recent research in psychology, education, and behavioral economics has started to recognize the importance of non-cognitive skills on many of life's successful outcomes. For example, 2015 OECD study analyzed about fostering social and emotional skills through families, schools, and communities (Ikesako \& Miyamoto, 2015).

"Cognitive characteristics" usually refer to ability and/or achievement test outcomes. The term "non-cognitive characteristics" refers to the very broad range of strategies, skills, attitudes, and behaviors which play an essential role in academic performance, but may not be captured by cognitive or achievement tests (Farrington et al., 2012).

These include metacognitive skills, motivation, self-esteem, creativity and personality traits (Heckman et al., 2006; Gutman \& Schoon, 2013). Less attention has been paid to these non-cognitive factors (Farrington et al., 2012). Nowadays, the importance of these "soft" skills is becoming more widely accepted (Else \& Alexander, 2018).

For example, research suggests that high achievement is not merely a consequence of cognitive factors such as high ability, but also non-cognitive factors which play perhaps an even more important role such as motivation, dedication, and hard work (Renzulli, 1978; Schneider, 2000; Heckman et al., 2006).

The concept of "non-cognitive skills" is blatantly broad and covers a wide array of phenomena that have been discussed using varying labels in different disciplines including self-efficacy, motivation, perseverance, self-control, social competence, resilience, coping, and creativity (Gutman \& Schoon 2013).

However, no single factor has yet emerged to date in the literature on personality and/or non-cognitive skills, and it is unlikely that one will ever be found, given the diversity of traits subsumed under the category of personality and/or non-cognitive skills.

On the other hand, in many countries, nearly all students attend schools, most of which provide some opportunities for engaging in both structured and unstructured physical activity. They have established time and other requirements for physical education in schools, while simultaneously schools are getting more pressure to meet academic requirements, resulting in inadequate allocation of time for physical education (Kelder et al., 2005). If physical education does not provide enough opportunities for students to achieve the moderately recommended amount of physical activity, it is necessary to select other physical activities. In fact, the number of physical activity programs after school has increased.

In 2017, a Japanese survey conducted by the Sports Agency found that the 
participation rate in the exercise department is $56.4 \%$ for male high school students, $27.1 \%$ for female high school students, and $41.9 \%$ overall.

Although the diversity of traits is a convoluting factor, our research continues to explore and analyze the relationship between experiences of athletic and daily life and personality.

Extra-curricular activities are another important means to enhance students' social and emotional skills. Club activities such as sport, music, and arts are potentially powerful medium through which children can foster social and emotional development while learning other specific skills.

In Japan, cross-sectional research suggests that participation in club activities is related to higher social and emotional skill levels. For example, Yamamoto, Araki and Kamino (2010) found that high school students participating in club activities had higher level of social and emotional skills related to achieving goals, expressing opinions, and working with others. Aoki (2005) also found a positive relationship between high school students' athletic club participation and their levels of social skills.

It is known that sport experiences have positive effects on an individual's life skills. However, correlations between motives for participating in exercise in daily life and individual personality and/or non-cognitive skills have not been examined to date.

Some studies reported findings with significant effects related to psychosocial constructs (e.g., body weight concerns, self-esteem, depression, self-efficacy, motivation, and parental support for physical activity) (Yolanda et al., 2017). Kelder et al. (2005) analyzed the self-efficacy toward activity participation and reported significantly improved psychological indicators.

We hypothesized that experiences of crisis, exploration, and commitment in athletic and daily life events affect personality and/or non-cognitive skills (Figure 1).

This study examined the relationship between experience of athletics and daily life on personality and/or non-cognitive skills in senior high school students.

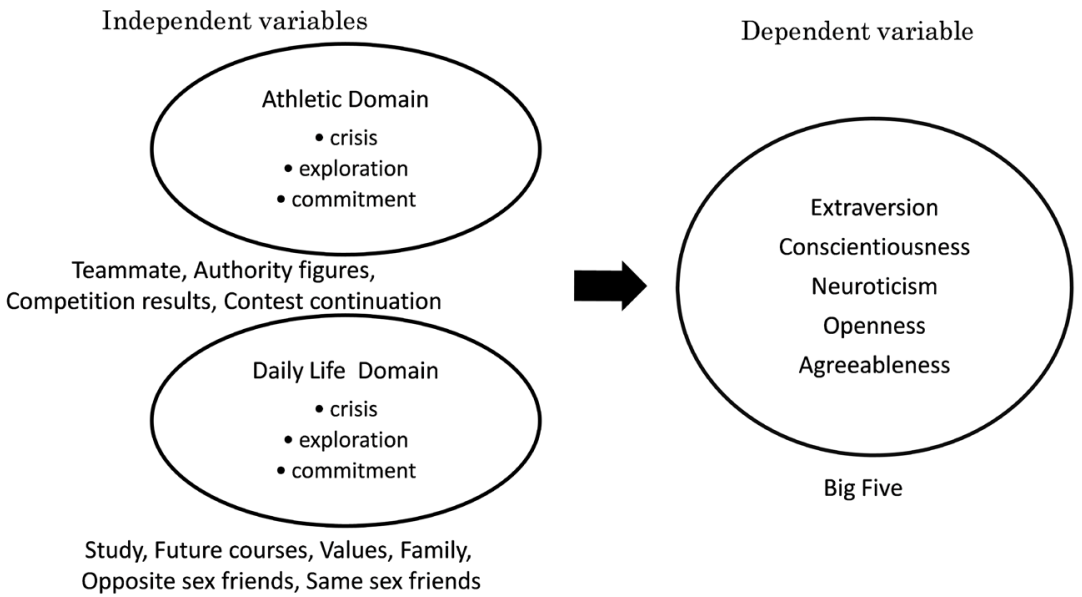

Figure 1. Model of relationship between experience and Big Five. 


\section{Methods}

\subsection{Subjects}

Senior high school students ( $\mathrm{n}=307$; 189 males and 118 females) in Japan completed a questionnaire assessing their experiences of crisis, exploration, and commitment on four issues (Teammates, Authority figures, Competition results, Contest continuation) in the athletic domain, and on six issues (Study, Future courses, Values, Family, Opposite sex friends, Same sex friends) in the daily life domain (Takenouchi et al., 2006). The age of respondents was 16 - 18 years. Their sporting experience from most common to least common is the following: Football ( $\mathrm{n}=51 ; 34$ males and 17 females), Basketball ( $\mathrm{n}=37 ; 19$ males and 18 females), Athletics ( $\mathrm{n}=34 ; 23$ males and 11 females), Boat $(\mathrm{n}=34 ; 23$ males and 11 females), Kendo ( $\mathrm{n}=29 ; 19$ males and 10 females), Handball $(\mathrm{n}=26 ; 14$ males and 12 females), Hockey ( $\mathrm{n}=21 ; 12$ males and 9 females), Shooting $(\mathrm{n}=$ 15; 7 males and 8 females), Archery ( $\mathrm{n}=14 ; 5$ males and 9 females), Canoeing ( $\mathrm{n}$ $=13 ; 7$ males and 6 females), Fencing $(\mathrm{n}=12 ; 5$ males and 7 females), Tennis ( $\mathrm{n}$ $=12 ; 12$ males $)$, and Water polo $(n=9 ; 9$ males $)$. All of the subjects participated in physical activities after school.

\subsection{Measurements}

We used the questionnaire used by Takenouchi et al. (2006), which includes the following:

Crisis: "To what extent have you been annoyed or worried about individual events so far?" ("1" = much less often - " 5 " = much more often).

Exploration: "How much effort did you put into solving the problem when you were annoyed or worried?" ("1" = much less - "5" = much more).

Commitment: "Now, how much do you emphasize the importance of solving the problem?" ("1" = much less - " 5 " = much more).

Personality was measured by the "Big Five". A short form of the Japanese Big-Five Scale was developed by Namikawa et al. (2012). This questionnaire measures five dimensions of personality: Extraversion, Conscientiousness, Neuroticism, Openness, and Agreeableness.

To guarantee the privacy of students' information all questionnaires were anonymous.

\subsection{Statistical Analysis}

In our study we used statistical techniques to analyze the data for inferences from our research data. The descriptive statistics used to summarize the data, and to investigate the survey questionnaire, formulating the hypotheses and the inferential statistics, were employed. All analyses were performed in IBM SPSS. 25 and $p<0.05$ was considered statistically significant. For all analyses, effect size (Cohen's $d$ for t-tests) was calculated. This methodology is based on statistical analysis, which in this paper includes multiple regression analysis. In our study the dependent variable consists of personality, while the independent va- 
riables are the following: their experience of crisis, exploration, and commitment in the athletic domain and the daily life domain (Figure 1).

In interpreting our results, we make use of the correspondence described in Mendez (2015) between these child qualities and the five personality factors in the "Big Five", which is the most influential classification of personality skills, and comparing our results to those in psychological literature. In this study we discuss how we think various experiences of high school athletes relate to the different dimensions of the "Big Five".

\section{Results and Discussion}

These averages and t-tests are shown in Table 1. Regarding Conscientiousness in the Big Five, Over 10 years of experience males $(M=12.94$; $S D=3.20)$ had significantly higher values than Less than 10 years of experience males $(\mathrm{M}=11.94$; $\mathrm{SD}=3.24), \mathrm{t}(187)=1.99 ; p<0.05 ; \mathrm{d}=0.31$ ( $\mathrm{d}$ is the effect size, Cohen, 1988), and Openness in the Big Five, Over 10 years of experience males $(\mathrm{M}=12.48$; $\mathrm{SD}=$ 2.84) had significantly higher values than Less than 10 years of experience males $(\mathrm{M}=11.46 ; \mathrm{SD}=3.49), \mathrm{t}(187)=2.14 ; p<0.05 ; \mathrm{d}=0.31$. On the other hand, regarding Neuroticism in the Big Five, Less than 10 years of experience males (M $=14.48 ; \mathrm{SD}=4.20)$ showed significantly higher than Over 10 years of experience males $(\mathrm{M}=13.08$; $\mathrm{SD}=3.68), \mathrm{t}(187)=2.34 ; p<0.05 ; \mathrm{d}=0.35$. There were no mean differences for crisis, exploration, commitment in the Athletic Domain; crisis, exploration, commitment in the Daily Life Domain, or Extraversion and Agreeableness in the Big Five.

Table 1. Mean and SD for experiences domains and Big Five with t-tests in males.

\begin{tabular}{|c|c|c|c|c|c|c|c|}
\hline & \multirow[t]{2}{*}{ Variables } & \multicolumn{2}{|c|}{$\begin{array}{l}\text { Less than } 10 \text { years } \\
\text { of experience } \\
(n=127)\end{array}$} & \multicolumn{2}{|c|}{$\begin{array}{l}\text { Over } 10 \text { years } \\
\text { of experience } \\
\quad(n=62)\end{array}$} & \multirow[t]{2}{*}{$t$} & \multirow[t]{2}{*}{$d$} \\
\hline & & M & $\mathrm{SD}$ & M & $\mathrm{SD}$ & & \\
\hline \multirow[t]{3}{*}{ Athletic Domain } & Crisis & 11.80 & 3.42 & 11.44 & 3.41 & 0.70 & 0.11 \\
\hline & Exploration & 13.46 & 4.37 & 14.00 & 4.64 & 0.77 & 0.12 \\
\hline & Commitment & 15.50 & 4.78 & 15.56 & 4.65 & 0.08 & 0.01 \\
\hline \multirow[t]{3}{*}{ Daily Life Domain } & Crisis & 13.32 & 4.25 & 13.73 & 4.33 & 0.60 & 0.09 \\
\hline & Exploration & 13.69 & 4.98 & 15.31 & 5.64 & 1.92 & 0.31 \\
\hline & Commitment & 15.87 & 5.62 & 16.82 & 5.74 & 1.07 & 0.17 \\
\hline \multirow[t]{5}{*}{ Big Five } & Extraversion & 13.41 & 4.22 & 14.10 & 3.57 & 1.17 & 0.17 \\
\hline & Conscientiousness & 11.94 & 3.24 & 12.94 & 3.20 & $1.99^{*}$ & 0.31 \\
\hline & Neuroticism & 14.48 & 4.20 & 13.08 & 3.68 & $2.34^{*}$ & 0.35 \\
\hline & Openness & 11.46 & 3.49 & 12.48 & 2.84 & $2.14^{*}$ & 0.31 \\
\hline & Agreeableness & 11.21 & 4.09 & 11.82 & 3.26 & 1.11 & 0.16 \\
\hline
\end{tabular}


These averages and t-tests are shown in Table 2. Regarding crisis in the Daily Life Domain, Less than 10 years of experience females $(M=13.41$; $S D=3.36)$ had significantly higher values than Over 10 years of experience females $(M=$ $11.56, \mathrm{SD}=3.22), \mathrm{t}(116)=2.23 ; p<0.05 ; \mathrm{d}=0.56$. There were no mean differences for crisis, exploration, commitment in the Athletic Domain, nor mean differences in exploration, and commitment in the Daily Life Domain; or regarding Extraversion, Conscientiousness, Neuroticism, Openness and Agreeableness in the Big Five.

Variables with their experience of crisis, exploration, and commitment in the athletic domain and the daily life domain were subject to multiple regression analysis with the Big Five (Extraversion, Conscientiousness, Neuroticism, Openness, Agreeableness) as the dependent variable. Examining the coefficients of determination indicated that some variables were significant at the $1 \%$ level. In males (Less than 10 years of experience), the significant predictor variables of Extraversion $(\mathrm{R} 2=0.26 ; \mathrm{F}(6,126)=7.15 ; p<0.01)$ in the resulting model were exploration in the Athletic Domain $(\beta=0.45 ; p<0.01)$ and exploration in the Daily Life Domain $(\beta=-0.37 ; p<0.05)$. Moreover, the significant predictor variables of Neuroticism $(\mathrm{R} 2=0.18 ; \mathrm{F}(6,126)=4.36 ; p<0.01)$ were exploration in the Daily Life Domain $(\beta=0.36 ; p<0.05)$ (Table 3$)$.

Furthermore, in males (Over 10 years of experience), the significant predictor variables of Neuroticism $(\mathrm{R} 2=0.23 ; \mathrm{F}(6,61)=2.73, p<0.05)$ in the resulting model were crisis in the Daily Life Domain $(\beta=0.46 ; p<0.05)$. Moreover, the significant predictor variables of Agreeableness $\left(\mathrm{R}^{2}=0.17 ; \mathrm{F}(6,61)=1.84 ; p=\right.$ n.s.) were commitment in the Athletic Domain $(\beta=-0.51 ; p<0.05)$ and commitment in the Daily Life Domain $(\beta=0.54 ; p<0.05)$ (Table 4$)$.

Table 2. Mean and SD for experiences domains and Big Five with t-tests in females.

\begin{tabular}{|c|c|c|c|c|c|c|c|}
\hline & \multirow[t]{2}{*}{ Variables } & \multicolumn{2}{|c|}{$\begin{array}{l}\text { Less than } 10 \text { years } \\
\text { of experience } \\
(n=100)\end{array}$} & \multicolumn{2}{|c|}{$\begin{array}{l}\text { Over } 10 \text { years } \\
\text { of experience } \\
\quad(n=18)\end{array}$} & \multirow[t]{2}{*}{$t$} & \multirow[t]{2}{*}{$d$} \\
\hline & & M & $\mathrm{SD}$ & M & $\mathrm{SD}$ & & \\
\hline \multirow[t]{3}{*}{ Athletic Domain } & Crisis & 13.21 & 3.37 & 12.44 & 3.05 & 0.96 & 0.23 \\
\hline & Exploration & 14.39 & 4.39 & 13.56 & 4.23 & 0.77 & 0.19 \\
\hline & Commitment & 15.16 & 4.58 & 13.67 & 5.25 & 1.13 & 0.32 \\
\hline \multirow[t]{3}{*}{ Daily Life Domain } & Crisis & 13.41 & 3.36 & 11.56 & 3.22 & $2.23^{*}$ & 0.56 \\
\hline & Exploration & 13.85 & 4.38 & 12.28 & 4.13 & 1.47 & 0.36 \\
\hline & Commitment & 14.69 & 5.15 & 13.50 & 6.56 & 0.73 & 0.22 \\
\hline \multirow[t]{5}{*}{ Big Five } & Extraversion & 13.48 & 3.36 & 13.39 & 2.87 & 0.12 & 0.03 \\
\hline & Conscientiousness & 12.78 & 3.22 & 11.67 & 3.27 & 1.33 & 0.34 \\
\hline & Neuroticism & 14.72 & 3.55 & 15.00 & 3.68 & 0.30 & 0.08 \\
\hline & Openness & 10.85 & 2.69 & 11.50 & 1.82 & 1.28 & 0.25 \\
\hline & Agreeableness & 12.80 & 3.34 & 13.06 & 3.02 & 0.33 & 0.08 \\
\hline
\end{tabular}

${ }^{*}: p<0.05$. 
Table 3. Multiple regression analysis predicting Big Five in males (less than 10 years of experience).

\begin{tabular}{|c|c|c|c|c|c|c|c|c|c|c|c|c|c|c|c|c|}
\hline & \multirow{2}{*}{ Variables } & \multicolumn{3}{|c|}{ Extraversion } & \multicolumn{3}{|c|}{ Conscientiousness } & \multicolumn{3}{|c|}{ Neuroticism } & \multicolumn{3}{|c|}{ Openness } & \multicolumn{3}{|c|}{ Agreeableness } \\
\hline & & $B$ & $\beta$ & $t$ & $B$ & $\beta$ & $t$ & $B$ & $\beta$ & $t$ & $B$ & $\beta$ & $t$ & $B$ & $\beta$ & $t$ \\
\hline \multirow[t]{3}{*}{ Athletic Domain } & Crisis & -0.04 & -0.04 & -0.26 & -0.06 & -0.07 & -0.42 & 0.26 & 0.21 & 1.45 & -0.02 & -0.02 & -0.12 & -0.18 & -0.15 & -0.97 \\
\hline & Exploration & 0.44 & 0.45 & $2.73^{* *}$ & 0.16 & 0.22 & 1.16 & -0.12 & -0.12 & -0.69 & 0.11 & 0.14 & 0.74 & 0.24 & 0.25 & 1.33 \\
\hline & Commitment & 0.22 & 0.24 & 1.61 & 0.13 & 0.19 & 1.08 & -0.11 & -0.12 & -0.77 & 0.01 & 0.02 & 0.12 & -0.13 & -0.15 & -0.89 \\
\hline \multirow[t]{4}{*}{ Daily Life Domain } & Crisis & 0.01 & 0.01 & 0.11 & 0.12 & 0.15 & 1.03 & 0.09 & 0.09 & 0.65 & -0.01 & -0.01 & -0.05 & 0.19 & 0.20 & 1.35 \\
\hline & Exploration & -0.31 & -0.37 & $-2.34^{*}$ & -0.19 & -0.29 & -1.61 & 0.30 & 0.36 & $2.15^{*}$ & -0.05 & -0.07 & -0.41 & -0.09 & -0.11 & -0.62 \\
\hline & Commitment & 0.14 & 0.18 & 1.20 & -0.02 & -0.03 & -0.20 & -0.08 & -0.10 & -0.65 & 0.13 & 0.21 & 1.24 & 0.08 & 0.11 & 0.61 \\
\hline & $\mathrm{R}^{2}\left(\Delta \mathrm{R}^{2}\right)$ & 0.26 & $0.23^{* *}$ & & 0.06 & 0.01 & & 0.18 & $0.14^{* *}$ & & 0.06 & 0.02 & & 0.04 & -0.01 & \\
\hline
\end{tabular}

${ }^{*}: p<0.05,{ }^{* *}: p<0.01$.

Table 4. Multiple regression analysis predicting Big Five in males (over 10 years of experience).

\begin{tabular}{|c|c|c|c|c|c|c|c|c|c|c|c|c|c|c|c|c|}
\hline & \multirow{2}{*}{ Variables } & \multicolumn{3}{|c|}{ Extraversion } & \multicolumn{3}{|c|}{ Conscientiousness } & \multicolumn{3}{|c|}{ Neuroticism } & \multicolumn{3}{|c|}{ Openness } & \multicolumn{3}{|c|}{ Agreeableness } \\
\hline & & $B$ & $\beta$ & $t$ & $B$ & $\beta$ & $t$ & $B$ & $\beta$ & $t$ & $B$ & $\beta$ & $t$ & $B$ & $\beta$ & $t$ \\
\hline \multirow[t]{3}{*}{ Athletic Domain } & Crisis & -0.07 & -0.07 & -0.32 & -0.07 & -0.07 & -0.32 & -0.03 & -0.03 & -0.13 & 0.14 & 0.17 & 0.73 & 0.13 & 0.14 & 0.62 \\
\hline & Exploration & -0.09 & -0.11 & -0.47 & -0.28 & -0.41 & -1.72 & 0.22 & 0.28 & 1.24 & -0.18 & -0.30 & -1.20 & 0.03 & 0.04 & 0.18 \\
\hline & Commitment & 0.12 & 0.16 & 0.76 & -0.04 & -0.05 & -0.25 & -0.18 & -0.22 & -1.10 & 0.21 & 0.34 & 1.55 & -0.36 & -0.51 & $-2.42^{\star}$ \\
\hline \multirow[t]{4}{*}{ Daily Life Domain } & Crisis & 0.25 & 0.30 & 1.40 & 0.20 & 0.26 & 1.24 & 0.39 & 0.46 & $2.26^{*}$ & -0.01 & -0.02 & -0.09 & 0.07 & 0.09 & 0.42 \\
\hline & Exploration & -0.22 & -0.35 & -1.30 & -0.08 & -0.14 & -0.53 & -0.13 & -0.20 & -0.80 & 0.02 & 0.03 & 0.12 & -0.07 & -0.12 & -0.47 \\
\hline & Commitment & 0.25 & 0.41 & 1.65 & 0.16 & 0.29 & 1.19 & 0.02 & 0.03 & 0.13 & 0.02 & 0.04 & 0.17 & 0.31 & 0.54 & $2.22^{*}$ \\
\hline & $\mathrm{R}^{2}\left(\Delta \mathrm{R}^{2}\right)$ & 0.14 & 0.05 & & 0.17 & 0.08 & & 0.23 & $0.15^{\star}$ & & 0.08 & -0.02 & & 0.17 & 0.08 & \\
\hline
\end{tabular}

${ }^{*}: p<0.05$.

In females (Less than 10 years of experience) there were no significant model of the Big Five and significant predictor variables (Table 5).

Furthermore, in females (Over 10 years of experience) the significant predictor variables of Agreeableness $(\mathrm{R} 2=0.55 ; \mathrm{F}(6,17)=2.26 ; p=\mathrm{n} . \mathrm{s}$.) were crisis in the Athletic Domain $(\beta=-0.87 ; p<0.05)$ (Table 6).

The results of multiple regression analysis are summarized in Figures 2-4.

Solid arrows represent significant partial regressions; dashed arrows show relationships that were included in the analysis but were not statistically significant in the whole model. For each significant relationship we label the corresponding solid arrow with the partial regression coefficient, $b$.

Multiple regression analyses with crisis, exploration, and commitment as independent variables and personality as the dependent variable revealed that for males with less than 10 years of experience, there were significant relationships between independent and dependent variables with regard to exploration in athletic domain and daily life domain; for males with over 10 years of experience, there were significant relationships between independent and dependent variables with regard to commitment in athletic domain, crisis and commitment 


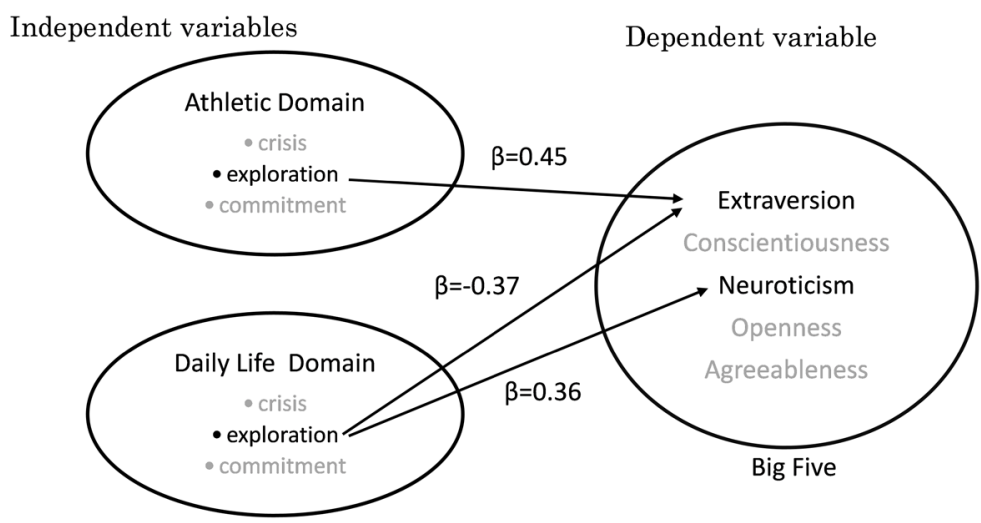

Figure 2. Results showing a relationship in model (less than 10 years of experience in males).

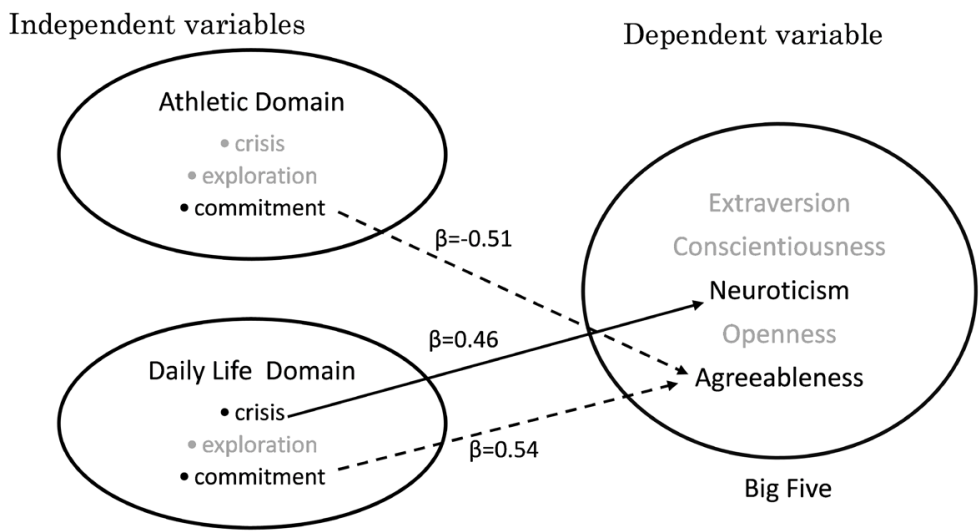

Figure 3. Results showing a relationship in model (over 10 years of experience in males).

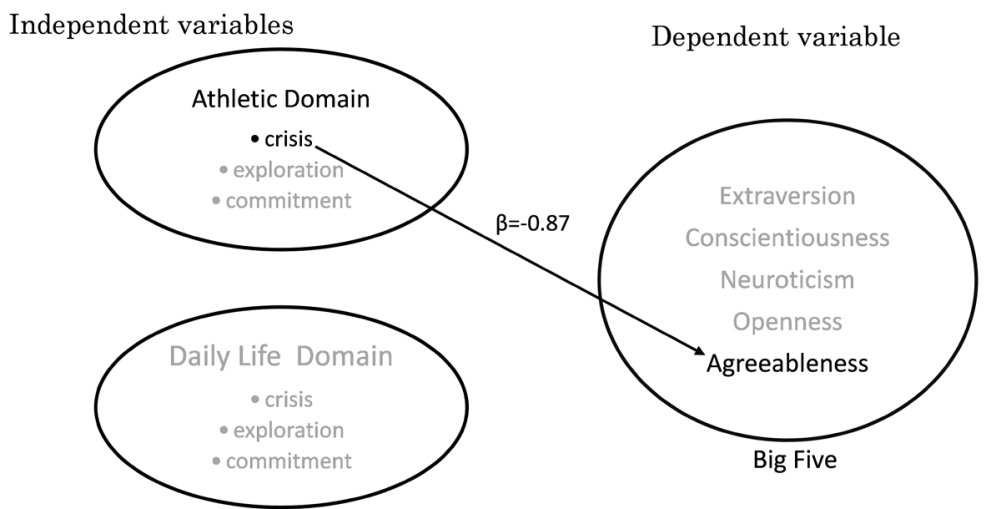

Figure 4. Results showing a relationship in model (over 10 years of experience in females).

in daily life domain. For females with less than 10 years of experience, there was no significant difference; for females with over 10 years of experience, there were significant relationships between independent and dependent variables with regard to crisis in athletic domain.

There was a more significant relationship between various experiences and personality in males than females. 
Table 5. Multiple regression analysis predicting Big Five in females (less than 10 years of experience).

\begin{tabular}{|c|c|c|c|c|c|c|c|c|c|c|c|c|c|c|c|c|}
\hline & \multirow{2}{*}{ Variables } & \multicolumn{3}{|c|}{ Extraversion } & \multicolumn{3}{|c|}{ Conscientiousness } & \multicolumn{3}{|c|}{ Neuroticism } & \multicolumn{3}{|c|}{ Openness } & \multicolumn{3}{|c|}{ Agreeableness } \\
\hline & & $B$ & $\beta$ & $t$ & $B$ & $\beta$ & $t$ & $B$ & $\beta$ & $t$ & $B$ & $\beta$ & $t$ & $B$ & $\beta$ & $t$ \\
\hline \multirow[t]{3}{*}{ Athletic Domain } & Crisis & 0.03 & 0.03 & 0.21 & 0.04 & 0.04 & 0.34 & 0.20 & 0.19 & 1.49 & -0.03 & -0.03 & -0.25 & 0.04 & 0.04 & 0.31 \\
\hline & Exploration & 0.11 & 0.14 & 0.76 & -0.01 & -0.02 & -0.10 & -0.13 & -0.16 & -0.85 & 0.10 & 0.17 & 0.84 & -0.03 & -0.04 & -0.19 \\
\hline & Commitment & 0.18 & 0.24 & 1.26 & -0.13 & -0.18 & -0.90 & 0.23 & 0.29 & 1.52 & -0.06 & -0.10 & -0.49 & -0.03 & -0.04 & -0.21 \\
\hline \multirow[t]{4}{*}{ Daily Life Domain } & Crisis & -0.25 & -0.25 & -1.83 & 0.25 & 0.26 & 1.79 & 0.22 & 0.20 & 1.48 & -0.11 & -0.13 & -0.90 & 0.18 & 0.18 & 1.24 \\
\hline & Exploration & 0.23 & 0.30 & 1.71 & -0.02 & -0.02 & -0.13 & 0.09 & 0.11 & 0.65 & 0.15 & 0.24 & 1.26 & 0.05 & 0.07 & 0.37 \\
\hline & Commitment & -0.09 & -0.14 & -0.74 & -0.11 & -0.18 & -0.88 & -0.16 & -0.22 & -1.16 & -0.10 & -0.19 & -0.94 & -0.10 & -0.16 & -0.77 \\
\hline & $\mathrm{R}^{2}\left(\Delta \mathrm{R}^{2}\right)$ & 0.15 & 0.09 & & 0.09 & 0.03 & & 0.15 & 0.09 & & 0.04 & -0.02 & & 0.03 & -0.03 & \\
\hline
\end{tabular}

Table 6. Multiple regression analysis predicting Big Five in females (over 10 years of experience).

\begin{tabular}{|c|c|c|c|c|c|c|c|c|c|c|c|c|c|c|c|c|}
\hline & \multirow{2}{*}{ Variables } & \multicolumn{3}{|c|}{ Extraversion } & \multicolumn{3}{|c|}{ Conscientiousness } & \multicolumn{3}{|c|}{ Neuroticism } & \multicolumn{3}{|c|}{ Openness } & \multicolumn{3}{|c|}{ Agreeableness } \\
\hline & & $B$ & $\beta$ & $t$ & $B$ & $\beta$ & $t$ & $B$ & $\beta$ & $t$ & $B$ & $\beta$ & $t$ & $B$ & $\beta$ & $t$ \\
\hline \multirow[t]{3}{*}{ Athletic Domain } & Crisis & -0.03 & -0.03 & 0.07 & -0.42 & -0.39 & -0.94 & 0.56 & 0.46 & 1.19 & -0.28 & -0.46 & -1.16 & -0.86 & -0.87 & $-2.59^{*}$ \\
\hline & Exploration & -0.58 & -0.86 & -1.42 & 0.15 & 0.20 & 0.32 & 0.16 & 0.18 & 0.31 & 0.02 & 0.05 & 0.09 & 0.50 & 0.71 & 1.43 \\
\hline & Commitment & 0.34 & 0.61 & 1.08 & 0.21 & 0.34 & 0.58 & -0.03 & -0.04 & -0.08 & -0.12 & -0.33 & -0.60 & -0.22 & -0.38 & -0.80 \\
\hline \multirow[t]{4}{*}{ Daily Life Domain } & Crisis & 0.35 & 0.40 & 1.09 & -0.31 & -0.31 & -0.82 & 0.12 & 0.11 & 0.30 & -0.08 & -0.14 & -0.40 & 0.46 & 0.50 & 1.64 \\
\hline & Exploration & 0.16 & 0.23 & 0.39 & 0.27 & 0.34 & 0.55 & -0.14 & -0.16 & -0.27 & 0.22 & 0.50 & 0.85 & 0.00 & 0.00 & -0.01 \\
\hline & Commitment & -0.38 & -0.86 & -1.15 & -0.20 & -0.41 & -0.53 & 0.25 & 0.45 & 0.63 & 0.02 & 0.06 & 0.08 & 0.12 & 0.25 & 0.41 \\
\hline & $\mathrm{R}^{2}\left(\Delta \mathrm{R}^{2}\right)$ & 0.34 & -0.01 & & 0.30 & -0.08 & & 0.41 & 0.08 & & 0.38 & 0.04 & & 0.55 & 0.31 & \\
\hline
\end{tabular}

${ }^{*}: p<0.05$.

Females are motivated differently than males, in relation to physical activity. Generally speaking, females have less ego and are less mastery-oriented than males; therefore caring less about their performance in relation to others (Egli, Bland, Melton, \& Czech, 2011; Su, McBride, \& Xiang, 2015). Their goals in relation to physical activity are more aligned to overall health, appearance, and physical attractiveness (Chowdhury, 2012; Molanorouzi et al., 2015; Morris, Clayton, Power, \& Han, 1995; Amy et al., 2017). This points to one factor of gender differences.

For males with less than 10 years of experience, it is important to make an individual effort to solve their own problems. For males with over 10 years of experience, commitment is important in life events. As you gain experience, personality traits will have greater influence of commitment over exploration.

Findings from this study suggest, especially in males, for personality and/or non-cognitive skills, there is a relationship between exploration and commitment rather than crisis of daily life when analyzing by gender, domain, and years of athletic experience.

Similar to previous research examining personality, this study highlights the 
importance of including experiences of crisis, exploration, and commitment when taking part in sports activity (Takenouchi et al., 2006).

In order to strengthen non-cognitive skills through physical activities, it is necessary to give students autonomy in planning and implementing their club activities and goals. By doing so, one is confronted with issues such as achieving goals, troubles with fellows, and problems with injuries or physical limitations. By committing and dealing with these tasks and issues one can alter non-cognitive skills mentioned in our research.

In the future, we should consider the relationship between positive events and personality and/or non-cognitive skills.

In this study, we analyzed only personality and the correlation between the experiences of athletic and the daily life, but the personality is only one of the various factors of the non-cognitive ability. We did not analyze relationships of other non-cognitive abilities. In several other literatures, multiple factors are assumed to be involved in non-cognitive abilities. Therefore, in order to correlate non-cognitive abilities with other subjects, analyzing each of the various factors that make up non-cognitive abilities is needed in future study. Furthermore, there is a need to study what factors of non-cognitive abilities are more important.

\section{Conclusion}

This study examined the relationship between experiences of athletic and daily life and personality and/or non-cognitive skills in senior high school students by using multiple regression analysis. The results indicated that some variables showed significant relationships.

Furthermore, our results concluded that the degree of influence was changed by the difference of years of experience. There was a significant relationship between experiences and personality in males compared to females.

For males with less than 10 years of experience, it is important to make an effort to solve their problem. For males with over 10 years of experience, commitment is important in life events. As you gain experience, personality traits will be more greatly influenced by commitment over exploration.

This raises the possibility that males may be particularly shown to develop personality and/or non-cognitive abilities by physical activity than females.

It is known that sport experiences have positive effects on an individual's life skills. In the future, effects of exercise experiences in daily life on another event should be investigated further.

Furthermore, there is a need to study what factors of non-cognitive abilities are more important.

\section{Conflicts of Interest}

The authors declare no conflicts of interest regarding the publication of this paper. 


\section{References}

Amy, E. W., Kanayo, U., Laura, Q., \& Dave, M. (2017). Mobile Technology Usage Mediates Gender Differences in Physical Activity. International Journal of Sport Psychology, 48, 643-659.

Aoki, K. (2005). Social Skills of High School Athletes and Its Correlates. Journal of National Olympics Memorial Youth Center, National Olympics Memorial Youth Center of Japan, 5, 25-34.

Chowdhury, D. (2012). Examining Rea Sons for Participation in Sport and Exercise Using the Physical Activity and Leisure Motivation Scale (P ALMS). Doctoral Dissertation, Melbourne: Victoria University.

Cohen, J. (1988). Statistical Power Analysis for the Behavioral Sciences (2nd ed.). Hillsdale, NJ: Lawrence Erlbaum.

Egli, T., Bland, H. W., Melton, B. F., \& Czech, D. R. (2011). Influence of Age, Sex, and Race on college Students' Exercise Motivation of Physical Activity. Journal of American College Health, 59, 399-406. https://doi.org/10.1080/07448481.2010.513074

Else, B., \& Alexander, M. (2018). Non-Cognitive Characteristics of Gifted Students with Learning Disabilities: An In-Depth Systematic Review. Frontiers in Psychology, 9, 504.

Farrington, C. A., Roderick, M., Allensworth, E., Nagaoka, J., Keyes, T. S., Johnson, D. W. et al. (2012). Teaching Adolescents to Become Learners: The Role of Noncognitive Factors in Shaping School Performance. Chicago, IL: University of Chicago Consortium on Chicago School Research.

Gutman, L. M., \& Schoon, I. (2013). The Impact of Non-Cognitive Skills on Outcomes for Young People (pp. 1-5). London: Education Endowment Foundation. Leading Education and Social Research.

Heckman, J. J., Stixrud, J., \& Urzua, S. (2006). The Effects of Cognitive and Noncognitive Abilities on Labor Market Outcomes and Social Behavior. Journal of Labor Economics, 24, 411-482. https://doi.org/10.1086/504455

Ikesako, H., \& Miyamoto, K. (2015). Fostering Social and Emotional Skills through Families, Schools and Communities: Summary of International Evidence and Implication for Japan's Educational Practices and Research. OECD Education Working Papers 121, OECD Publishing.

Kelder, S., Hoelscher, D. M., Barroso, C. S., Walker, J. L., Cribb, P., \& Hu, S. (2005). The CATCH Kids Club: A Pilot After-School Study for Improving Elementary Students' Nutrition and Physical Activity. Public Health Nutrition, 8, 133-140. https://doi.org/10.1079/PHN2004678

Mendez, I. (2015). The Effect of the Intergenerational Transmission of Noncognitive Skills on Student Performance. Economics of Education Review, 46, 78-97. https://doi.org/10.1016/j.econedurev.2015.03.001

Molanorouzi, K., Khoo, S., \& Morris, T. (2015). Motives for Adult Participation in Physical Activity: Type of Activity, Age, and Gender. BMC Public Health, 15, 66. https://doi.org/10.1186/s12889-015-1429-7

Morris, T., Clayton, H., Power, H., \& Han, J. (1995). Activity Type Differences in Participation Motives. Australian Journal of Psychology, 47, 101-102.

Namikawa, T., Tani, I., Wakita, T., Kumagai, R., Nakane, A., \& Noguchi, H. (2012). Development of a Short Form of the Japanese Big-Five Scale, and a Test of Its Reliability and Validity. The Japanese Journal of Psychology, 83, 91-99.

https://doi.org/10.4992/jjpsy.83.91

Renzulli, J. S. (1978). What Makes Giftedness? Re-Examining a Definition. Phi Delta 
Kappan, 60, 180-184.

Schneider, W. (2000). Giftedness, Expertise, and (Exceptional) Performance: A Developmental Perspective. In K. A. Heller, F. J. Mönks, R. J. Sternberg, \& R. F. Subotnik (Eds.), International Handbook of Giftedness and Talent (pp. 165-179). Amsterdam: Elsevier.

Su, X., McBride, R. E., \& Xiang, P. (2015). College Students' Achievement Goal Orientation and Motivational Regulations in Physical Activity Classes: A Test of Gender Invariance. Journal of Teaching in Physical Education, 34, 2-17. https://doi.org/10.1123/jtpe.2013-0151

Takenouchi, T., Taguchi, T., \& Okuda, A. (2006). Personality Development in Junior and Senior High School Athletes: Focusing on Ego Development. Japan Journal of Physical Education, Health and Sport Sciences, 51, 757-771.

https://doi.org/10.5432/jjpehss.51.757

Yamamoto, K., Araki, S., \& Kamino, K. (2010). Empirical Study on Relation between Involvement in Extracurricular Activities and Acquisition of Sociality. NIT, Tsuyama College, 52, 95-100.

Yolanda, D., Fiona, G., Thomas, L., \& McKenzie (2017). After-School Physical Activity Interventions on Child and Adolescent Physical Activity and Health: A Review of Reviews. Advances in Physical Education, 7, 191-216.

https://doi.org/10.4236/ape.2017.72017 